\title{
Step-Ladder Expansive Cranioplasty: A Study on a Cadaveric Model
}

\author{
Sudip Kumar Sengupta ${ }^{1}$ Sanjeev Tandon ${ }^{2}$ Indra Bahadur Sahi \\ ${ }^{1}$ Department of Neurosurgery, Command Hospital (EC) Kolkata, \\ Kolkata, West Bengal, India \\ 2Department of Surgery, Command Hospital (EC) Kolkata, Kolkata, \\ West Bengal, India \\ Address for correspondence Sudip Kumar Sengupta, MS (Gen Surg), \\ MCh, Department of Neurosurgery, Command Hospital (EC) Kolkata, \\ 349/2, Dakshin Behala Road, Kolkata 700061 West Bengal, India \\ (e-mail: sudipkumarsengupta14@rediffmail.com).
}

Indian J Neurosurg 2018;7:16-22

\begin{abstract}
Keywords

- decompressive hemicraniectomy

- step-ladder expansive cranioplasty

- cadaveric model

Notwithstanding the ongoing debates on the necessity, indication, extent, and technique of achieving decompressive hemicraniectomy (DC), any procedure that can deliver the envisaged advantages of a DC, without having to take up the patient for a second surgery in the form of cranioplasty, can be of a great advantage in situations in which DC is being used.

Step-ladder expansive cranioplasty has been proposed as an effective single-step alternative to DC and cranioplasty at a later date, resulting in a fixed but assured volume augmentation. Recently, a case report has emerged documenting a successfully managed case of acute subdural hematoma (SDH) using this technique. In the present in vitro study, an attempt has been made to evaluate different variants of step-ladder expansive cranioplasty constructs using cadaver and clay models.

The findings suggest that the cranial volume expansion in step-ladder expansive cranioplasty is not dependent solely on the patient's skull bone thickness. If the clinical trials prove the procedure to be safe, it can be used at one end, as an alternative to preserving the bone flap at another site prior to cranioplasty, and as a complete onestage alternative to DC and cranioplasty at a later date, on the other.
\end{abstract}

\section{Introduction}

"Step-ladder expansive cranioplasty" has been proposed as an effective single-step alternative to a decompressive hemicraniectomy (DC) and cranioplasty at a later date, ${ }^{1,2}$ when a fixed but assured intracranial volume augmentation can be achieved. Recently a case report has been published describing successful application of "step-ladder expansive cranioplasty" for acute SDH. ${ }^{3}$ This technique utilizes the thickness of the skull bone for volume expansion. The "step ladder" can be designed in different ways with unique advantages and limitations of each of them. Existing literature is inadequate to help resolve many of the questions that need to be answered before formulizing and embarking on a prospective study to evaluate this promising novel technique. An attempt has been made in the present study to evaluate different variants of "step-ladder" expansive cranioplasty constructs, on cadaver and clay models, regarding their ability to allow lateral expansion of the dural bag.

The present study, on a cadaveric model, helps us improve our understanding about a few aspects that can be used in planning future surgeries. Whether the knowledge so acquired will translate into any clinical benefit will only become evident after trying them in clinical practice.

\section{Material and Methods}

A bone flap discarded after DC was collected with the permission of the next of kin, autoclaved and used for the study. Bone flap was measured along its convexity with a measuring tape. All the different "step-ladder" variations were designed sequentially using that single bone flap.
Copyright (C2018 Neurological

Surgeons' Society of India
License terms

() (1) $\Theta \circledast$ 
Imprint of the bone flap was taken on a clay plate and a hole was made in the plate that could represent craniotomy defect ( $\boldsymbol{- \text { Fig. }}$ 1A). CT scan of the clay plate was done and surface area $(S)$ of the craniectomy defect was measured (-Fig. 1B).

Different variants of cranioplasty constructs were designed as follows:

1. Single-step step ladder: Using the techniques recommended by Sengupta, ${ }^{1}$ titanium miniplates were fixed on the inner table of the bone flap and outer table of the cranium around the craniotomy defect. While fixing the bone flap, miniplates were bent at different angles and studied separately (-Fig. 1C).

2. "Gradual slope" step ladder: Bone flap was cut with a Midas-Rex pneumatic drill into two pieces by cutting along a line parallel to and at 2-cm distance from the anterior, medial, and posterior edges of the flap ( - Fig. 2 C). Holes wide enough to allow insertion of titanium miniplates, were drilled from the sides of the flap into the diploe at half the width of the bone in both the pieces of the bone flap ( - Fig. 3A). One end of titanium miniplates were inserted into the holes created in the inner bone piece and the other ends were fixed on the outer table of the outer bone piece ( - Fig. 3B).

Computed tomographic (CT) scans were obtained for all the different constructs. On CT scan images, increments achieved in the distance of the inner plate from the craniectomy margin $(\mathrm{H})$ and from the preprocedure state $(\mathrm{h})$ were measured.

\section{Study Models for Floating and Fixed Variants of "Gradual Slope" Step Ladder}

1. Fixed variant: By fixing the distal ends of the miniplates inserted into the diploe of the outer bone piece on the clay plate representing the outer table of cranium, the "fixed" variant was made ( - Fig. 4 A, B).

2. Floating variant: For a "Floating" variant of "gradual slope" step ladder, holes were drilled into the sides of the clay plate (representing diploe of the cranium at craniotomy edge) and miniplates were inserted into them. "Gradual slope" step-ladder construct was simply made to sit over these miniplates without any screws to fix each other (-Fig. 4C).

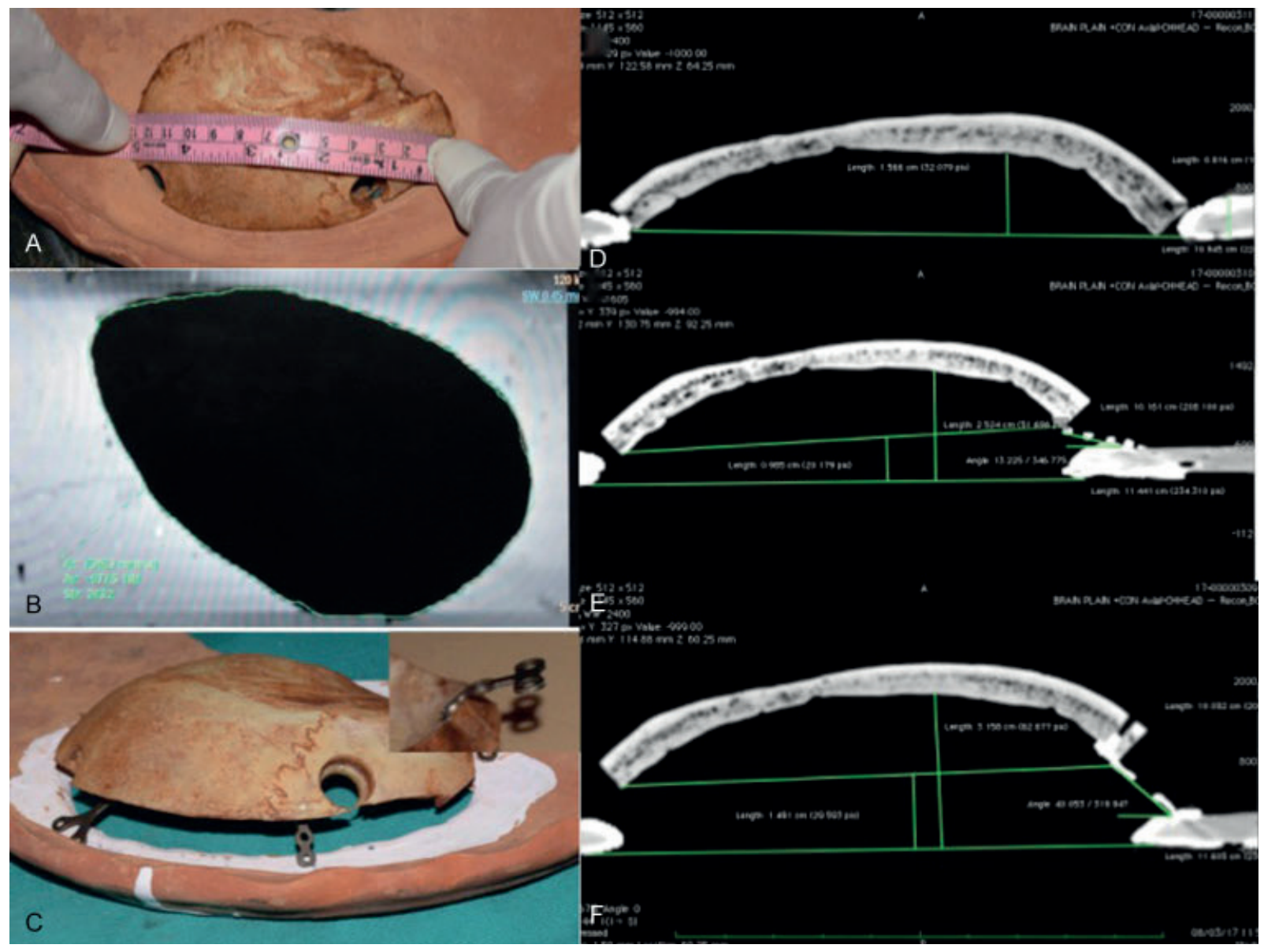

Fig. 1 Single-step step-ladder cranioplasty: (A) photograph of the cadaveric bone flap $13 \mathrm{~cm} \times 8 \mathrm{~cm}$ in size placed over a defect created in a clay plate, representing the craniotomy defect. (B) Surface area of the defect $\left(7,048 \mathrm{~mm}^{2}\right)$ measured on coronal reconstruction image on CT scan (C) photograph showing single-step step-ladder cranioplasty flap fixed at the edges of the craniotomy defect. Inset shows the titanium miniplate bent appropriately to change its angle of inclination. (D-F) Axial sections of CT scan images showing the bone plate at its preoperative level and after step-ladder cranioplasty with different angulations of the miniplates, respectively. 


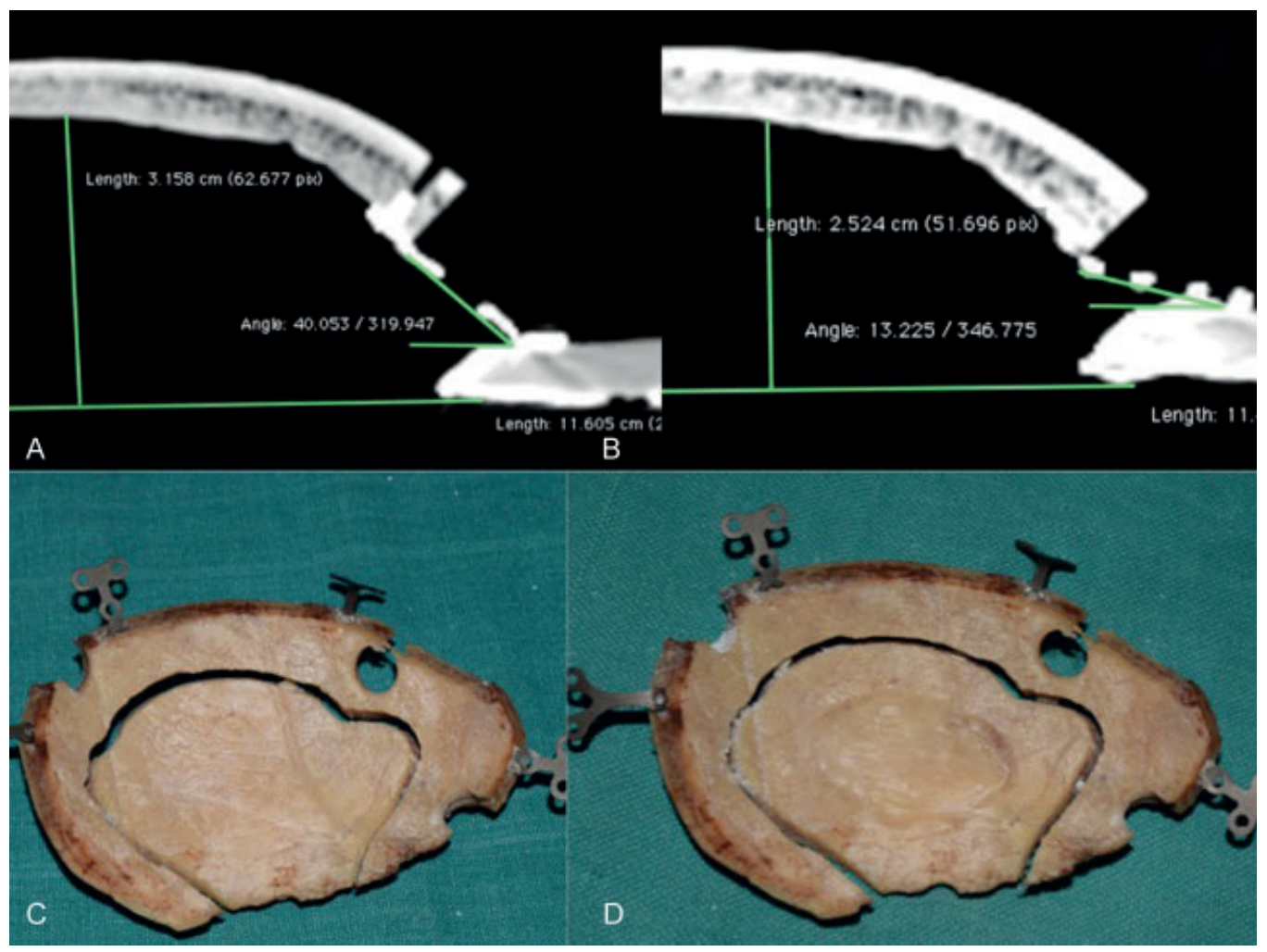

Fig. 2 Methods to increase intracranial volume for a craniotomy defect of given size: (A, B) NCCT images of the cranioplasty constructs in axial section showing an increase in displacement by $6 \mathrm{~mm}$ (from 2.5 to $3.1 \mathrm{~cm}$ ) on increasing the angle of inclination of the titanium miniplates used to fix the bone flap from 13 to 40 degrees. (C) A two-step expansive cranioplasty construct. (D) Coring out the inner table and part of diploe from the central part of the construct.

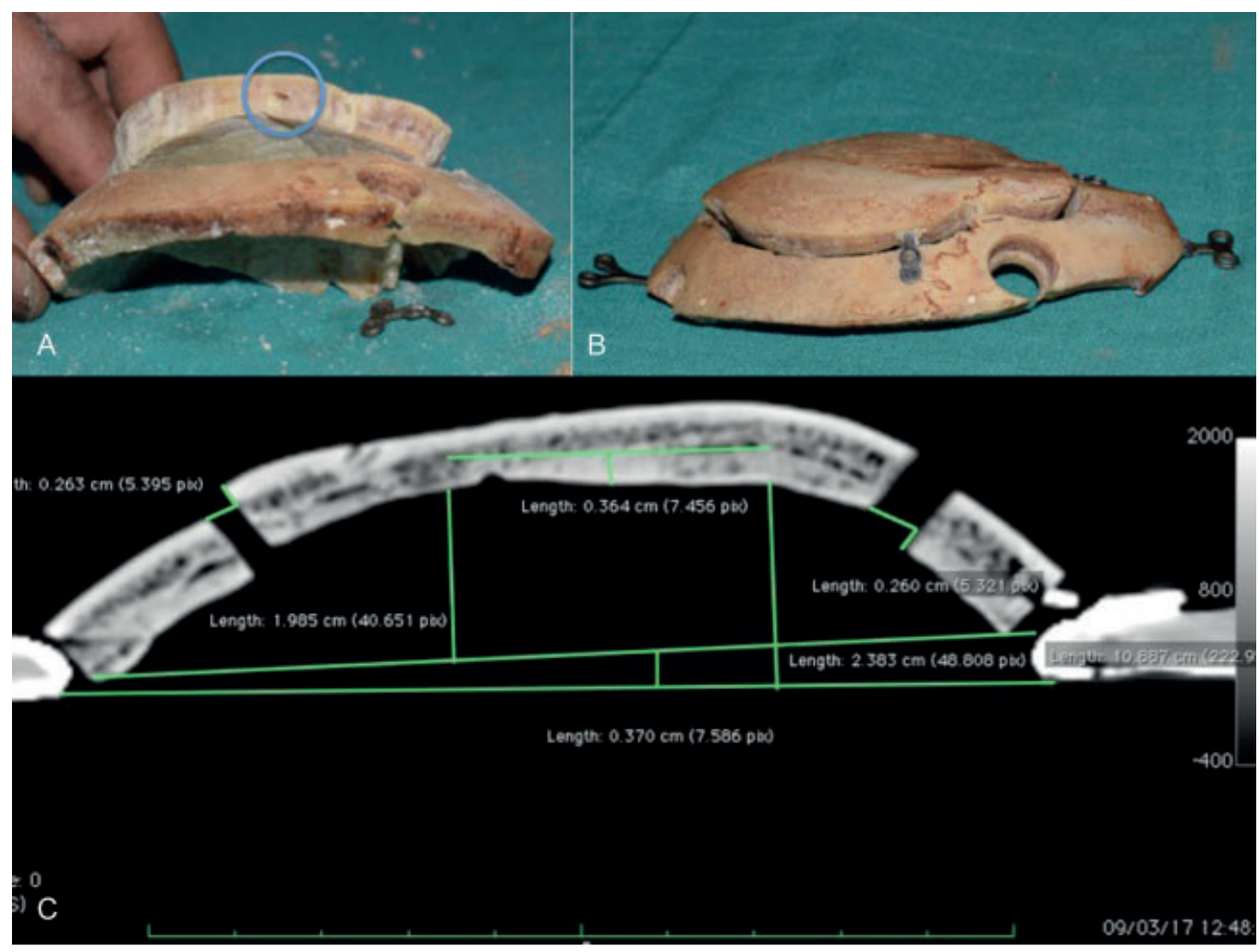

Fig. 3 Concept of gradual slope step-ladder cranioplasty construct: (A) Bone flap cut into two pieces with holes drilled into the edges of the bone plates in the diploe. (B) Titanium miniplates inserted into the sides of the bone through the holes in the diploe. The distal ends of the miniplates fixed over the outer cortex of the proximal (in relation to the craniotomy) bone flap. (C) Axial section of CT scan image of the construct showing 2.8 mm lateral displacement of the flap in each step of the construct. 


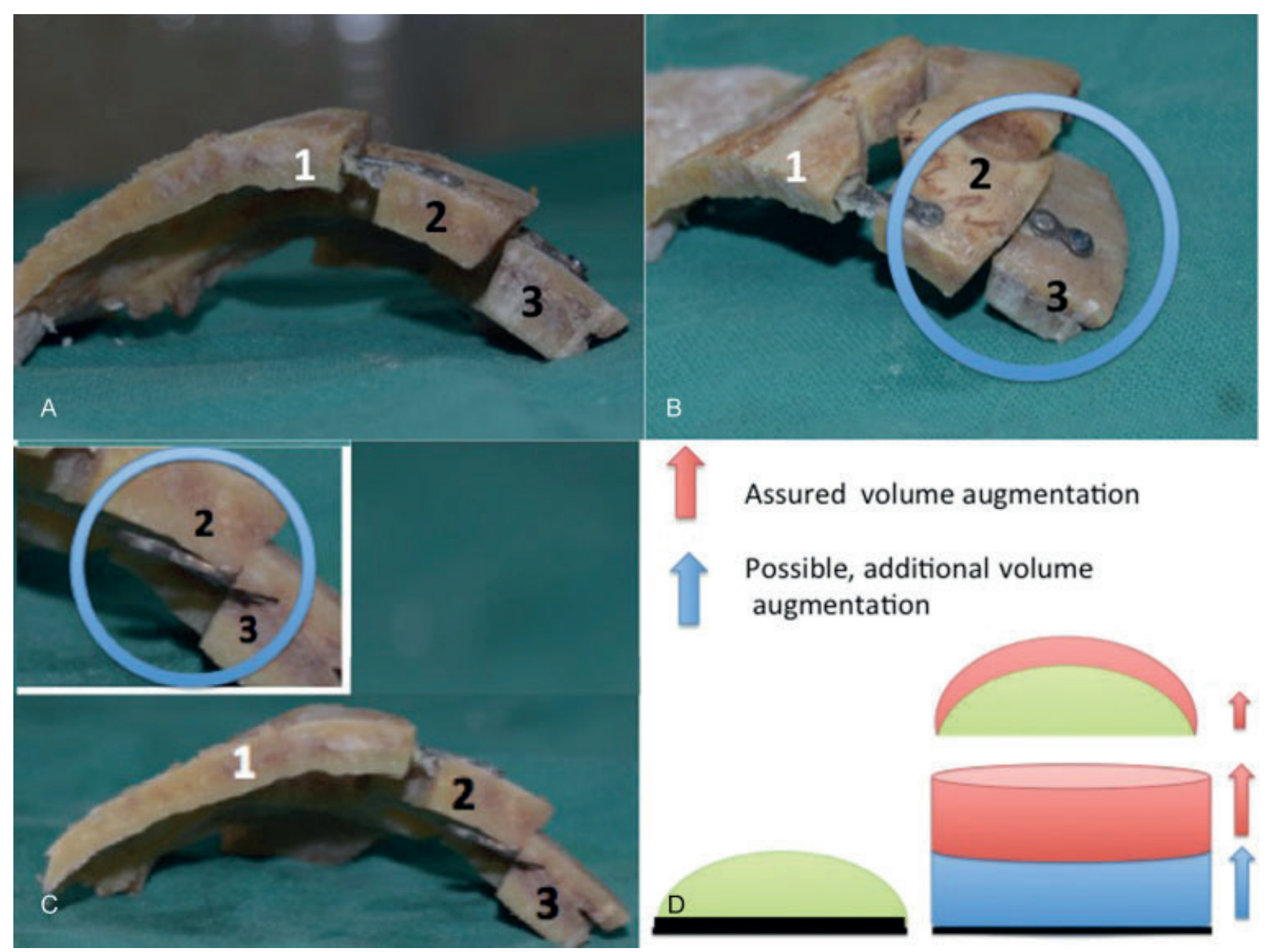

Fig. 4 Concept of fixed and mobile gradual slope expansive cranioplasty: (A, B) Fixed model: craniotomy construct fixed over the outer cortex of cranium with miniplates and screws. (C) Floating model: titanium miniplate inserted into a hole drilled into the diploe of the bone at craniotomy edge. Expansive cranioplasty construct placed loosely over the miniplate without screw fixation (inset showing closer view at craniectomy edge). (D) Diagrammatic presentation of volume changes with mobile model of expansive cranioplasty: Black border represents the level of inner table at the craniotomy margin. Green area represents intracranial the volume contained in the craniotomy bone flap. Red crescent-shaped area represents the volume augmentation achieved by reshaping the bone flap. Red cylindrical area represents fixed volume expansion due to outward displacement of the craniotomy flap held away by the titanium miniplates. Blue cylindrical area represents the volume expansion achieved by bone flap being pushed away by edematous brain in Floating model. (1) Distal bone flap. (2) Proximal bone flap. (3) Cranium at craniotomy margin.

\section{Results}

Removal of a $13-\times 8-\mathrm{cm}$ free bone flap resulted in a craniectomy defect of $10.2 \times 5.3 \mathrm{~cm}$ with a surface area of $7,048 \mathrm{~mm}^{2}$, as measured on CT scan (-Fig. 1B). Width of the bone flap was maximum at the level of the superior temporal line $(10 \mathrm{~mm})$. The portion of the bone flap medial to the superior temporal line was thicker (thickness of medial edge $9 \mathrm{~mm}$, measured at the coronal plane of parietal eminence) than the portion lateral to it (thickness of lateral edge $3 \mathrm{~mm}$, measured at the coronal plane of parietal eminence). Measured with the bone flap placed over the craniotomy margin (represented by the hole in the clay plate), when measured at the coronal plane of parietal eminence, the distance of the inner table from the craniotomy margin in the model was $17.2 \mathrm{~mm}$ (-Fig. 1D). The distance increased to $31.5 \mathrm{~mm}$ and $25.2 \mathrm{~mm}$, respectively, for $40-$ and 13-degree angles of the titanium miniplates as measured from a tangent drawn on the cranium at the edge of the craniectomy, for a single-step step-ladder cranioplasty (-Fig. 1E, F).
In multiple step "gradual slope" technique, single step increased the distance of the inner table by $2.6 \mathrm{~mm}$ and the distance of the inner table from the craniotomy margin was $23.8 \mathrm{~mm}$ in our model ( - Fig. 3C). An additional increment of $3.6 \mathrm{~mm}$ was found achievable by coring out part of the bone plate till the outer table. Volume of the space contained within the bone flap in preprocedure state was $52.9 \mathrm{~cm}^{3}$ as measured on CT scan images.

Results are summarized in - Table $\mathbf{1}$.

\section{Discussion}

Literature is replete with claims of success and failures of DC in various situations to keep the scientific community on its toes. We will deliberately avoid any discussion on these lines. Our aim is to see whether after achieving all that a given craniectomy had to achieve the bone flap can be placed back over the craniectomy defect, without nullifying the cranial volume expansion. To meet this aim, various novel techniques have been tried successfully and case series have been published. ${ }^{4-7}$ In all these techniques, bone flap is left under the scalp, hitched to the (or, as in one variant without any 
Table 1 Summary and analysis of the findings of the study

\begin{tabular}{|c|c|c|c|c|c|}
\hline \multirow[t]{2}{*}{$\begin{array}{l}\text { Sr. } \\
\text { no. }\end{array}$} & \multirow[t]{2}{*}{ Name of the procedure } & \multirow{2}{*}{$\begin{array}{l}\text { Craniotomy } \\
\text { surface area } \\
\text { (S) } \mathrm{mm}^{2}\end{array}$} & \multicolumn{2}{|c|}{$\begin{array}{l}\text { Lateral displacement of } \\
\text { inner table }\end{array}$} & \multirow{2}{*}{$\begin{array}{l}\text { Remarks } \\
\text { (Based on the findings of this study; } \\
\text { requires validation in clinical trials) }\end{array}$} \\
\hline & & & $\begin{array}{l}\text { From } \\
\text { craniectomy } \\
\text { margin } \\
\text { (H) }\end{array}$ & $\begin{array}{l}\text { From pre- } \\
\text { procedure } \\
\text { position } \\
\text { (h) }\end{array}$ & \\
\hline 1. & $\begin{array}{l}\text { Single-step step-ladder } \\
\text { expansive cranioplasty } \\
\text { 13-degree miniplate } \\
\text { inclination }\end{array}$ & 7,048 & $25.2 \mathrm{~mm}$ & $10.4 \mathrm{~mm}$ & \multirow{2}{*}{$\begin{array}{l}\text { A. Advantages } \\
\text { 1. Less operating time } \\
\text { 2. Maximum volume augmentation } \\
\text { 3. Easy to convert to formal hemicra- } \\
\text { niectomy (esp. during clinical trials) } \\
\text { 4. Easy to perform formal cranioplasty } \\
\text { at a later date, if required } \\
\text { B. Disadvantages } \\
\text { 1. Likelihood of bony nonunion } \\
\text { 2. Poor cosmesis }\end{array}$} \\
\hline 2. & $\begin{array}{l}\text { Single-step step-ladder } \\
\text { expansive cranioplasty } \\
\text { 40-degree miniplate } \\
\text { inclination }\end{array}$ & -do- & $31.5 \mathrm{~mm}$ & $15.9 \mathrm{~mm}$ & \\
\hline 3. & $\begin{array}{l}\text { Two-step step-ladder } \\
\text { expansive cranioplasty }\end{array}$ & \multicolumn{4}{|c|}{$\begin{array}{l}\text { In light of the understanding achieved by the present study, there is no indication for this } \\
\text { procedure. }\end{array}$} \\
\hline \multirow[t]{2}{*}{4.} & $\begin{array}{l}\text { Gradual slope } \\
\text { cranioplasty } \\
\text { "fixed model" }\end{array}$ & -do- & \multirow[t]{2}{*}{$23.8 \mathrm{~mm}$} & \multirow[t]{2}{*}{$8 \mathrm{~mm}$} & $\begin{array}{l}\text { A. Advantages } \\
\text { 1. In view of the bony contact, increased } \\
\quad \text { likelihood of bony union } \\
\text { 2. Better cosmesis } \\
\text { B. Disadvantages } \\
\text { 1. Lesser cranial volume augmentation } \\
\text { 2. More operating time } \\
\text { 3. Requires more skill/diligence }\end{array}$ \\
\hline & $\begin{array}{l}\text { Assured component of } \\
\text { "free floating model" }\end{array}$ & -do- & & & $\begin{array}{l}\text { Scope for further expansion in face of } \\
\text { raised ICP }\end{array}$ \\
\hline
\end{tabular}

Abbreviation: ICP, intracranial pressure.

anchoring to bone margins ${ }^{8}$ ) craniectomy margin in such a way that the flap(s) can move outward when pushed by the swollen brain, achieving cranial volume expansion. The authors have claimed good results of each of these variants on clinical outcome,, 78 intracranial pressure (ICP) reduction, and intracranial volume augmentation. ${ }^{4,5}$ Conceptually, dural sac with raised ICP has to push against the tensile strength of the scalp to achieve the volume augmentation. Placing the bone flaps between the scalp and dura, arguably, will reduce the available space. This is evident in most studies that show $5 \mathrm{~mm}$ less of lateral expansion of the brain in single-stage procedures $^{9}$ as compared with classic DC. ${ }^{2,10}$ Only exception to this finding has been the report by Peethambaran and Valsalmony, ${ }^{7}$ where the lateral expansion has been shown to be more with modified technique than the classic DC group. In this study, however, volume and ICP measurements have not been reported. One explanation of this fallacy could be assumption of a more conical shape by the prolapsing brain in a four-quadrant technique. A literature search revealed six studies ${ }^{210-14}$ in which classic unilateral frontotemporoparietal craniectomies have been studied for their surface area, volume expansion, and extent of dural outpouching through the craniectomy defects. Similarly, studies detailing the volumetric analysis of the modified techniques were reviewed. ${ }^{4-6}$ Findings of all the studies have been summarized in - Table 2. Findings of the present study have also been tabulated alongside to enable an easy comparison. It is evident that single-step step ladder with 40-degree plate angulation can achieve greater increase in the distance of inner plate from the craniectomy margin than the median achieved in the study by Cavuşoğlu et al, however, still remaining less than the maximum reported in the study and the mean reported by Fletcher et al. The single-step step ladder with 17-degree plate angulation and gradual slope multiple-step cranioplasty achieved a lateral displacement comparable to that reported by Kenning et $\mathrm{al}^{4}$ and Sengupta et $\mathrm{al}^{2}{ }^{2}$ The studies in which the lateral displacement of the dural margin from the preoperative state has been reported, the results in all the three variants in the cadaveric models were comparable to them. ${ }^{2,10}$

All the studies suffer from an inherent fallacy in trying to compare human skulls and brains of different size, shape, and volume. The extent of dural outpouching is also expected to depend on the ICP at the point where CT scans were done. In the present study, all the models were made from a single cadaveric cranial bone piece; hence the surface area of the craniectomy defect (reproduced by a clay model), shape of the bone flap, and the preprocedure volume of the space contained in the flap were constant. The surface area over which all the calculations were made $\left(7,048 \mathrm{~mm}^{2}\right)$ did not take into account the part contributed by temporal craniectomy. We have not measured the volume expansion by different models since the cranial volume expansion is unlikely to translate into equivalent volume expansion of the dural sac. 


\begin{tabular}{|c|c|c|c|c|c|c|c|}
\hline \multirow[t]{3}{*}{ SI. no. } & \multirow[t]{3}{*}{ Study } & \multirow{3}{*}{$\begin{array}{l}\text { No. of } \\
\text { cases }\end{array}$} & \multicolumn{4}{|l|}{ Parameters measured } & \multirow[t]{3}{*}{ Remarks } \\
\hline & & & \multirow{2}{*}{$\begin{array}{l}\text { Craniectomy surface } \\
\text { area recorded in the } \\
\text { study }\left(\mathrm{cm}^{2}\right)\end{array}$} & \multirow{2}{*}{$\begin{array}{l}\text { Volume } \\
\text { expansion } \\
\left(\mathrm{cm}^{3}\right)\end{array}$} & \multicolumn{2}{|c|}{ Height of the dural outpouching $(\mathrm{cm})$} & \\
\hline & & & & & $\begin{array}{l}\text { From craniectomy } \\
\text { margin }\end{array}$ & $\begin{array}{l}\text { From preoperative } \\
\text { level }\end{array}$ & \\
\hline 1. & Münch et al ${ }^{11}$ & 49 & $67.9 \pm 15.5$ & $92.6 \pm 65$ & - & - & \\
\hline 2. & Cavuşoğlu et al ${ }^{13}$ & 33 & $\begin{array}{l}\text { Median } 67.9 \\
\text { Max } 113\end{array}$ & $\begin{array}{l}\text { Median } 67.5 \\
\text { Max } 107.2\end{array}$ & $\begin{array}{l}\text { Median } 2.85 \\
\text { Max } 3.80\end{array}$ & & \\
\hline 3. & Olivecrona et al ${ }^{12}$ & 21 & $88 \pm 7$ & $98 \pm 11$ & - & - & $\begin{array}{l}\text { The bulging of the brain was estimated to be } \\
10 \% \text { of the mean diameter of the craniectomy and } \\
\text { volume measured accordingly }\end{array}$ \\
\hline \multirow[t]{3}{*}{4.} & \multicolumn{3}{|l|}{ Kenning et al ${ }^{4}$} & & & & \multirow{6}{*}{$\begin{array}{l}\text { Height of the dural outpouching from craniecto- } \\
\text { my margin has been referred to as extracerebral } \\
\text { herniation in these two studies }\end{array}$} \\
\hline & Hinge craniotomy & 20 & - & $77.5 \pm 54.1$ & $2.12 \pm 0.95$ & - & \\
\hline & $\begin{array}{l}\text { Decompressive } \\
\text { hemicraniectomy }\end{array}$ & 30 & - & $105.1 \pm 65.1$ & $2.60 \pm 0.77$ & - & \\
\hline \multirow[t]{3}{*}{5.} & Kenning et $\mathrm{al}^{5}$ & & & & & & \\
\hline & Hinge craniotomy & 09 & & $77.6 \pm 44.7$ & $2.59 \pm 0.76$ & & \\
\hline & $\begin{array}{l}\text { Decompressive } \\
\text { hemicraniectomy }\end{array}$ & 19 & & $96.3 \pm 54.4$ & $2.93 \pm 0.67$ & & \\
\hline 6. & Fletcher et al ${ }^{14}$ & 10 & & 107.3, SD 54.2 & Mean 2.98" & - & "Referred to as external cerebral herniation \\
\hline 7. & Sengupta et $\mathrm{al}^{2}$ & 06 & $\begin{array}{l}\text { Mean 66.89 } \\
(\text { Max 81.32, Min 54.22) }\end{array}$ & & $\begin{array}{l}\text { Mean 2.25 } \\
(\operatorname{Max} 2.7, \operatorname{Min} 2.2)\end{array}$ & $\begin{array}{l}\text { Mean 1.2 } \\
(\text { Max, 1.4 Min 0.7) }\end{array}$ & Height inversely proportional to surface area \\
\hline 8. & Kwon et $\mathrm{al}^{10}$ & 26 & & & & Mean $0.91^{*}$ & $\begin{array}{l}\text { * Referred to as mean swelling above bone flap } \\
\text { margin, in the study }\end{array}$ \\
\hline \multirow[t]{3}{*}{9.} & \multicolumn{6}{|c|}{ Peethambaran and Valsalmony ${ }^{7}$} & Mean ipsilateral brain width \\
\hline & $\begin{array}{l}\text { Four-quadrant } \\
\text { osteoplastic } \\
\text { craniotomy technique }\end{array}$ & 10 & & & & & Preoperative $65.7 \pm 4.97$, postoperative $76 \pm 4.62$ \\
\hline & $\begin{array}{l}\text { Decompressive } \\
\text { hemicraniectomy }\end{array}$ & 10 & & & & & $\begin{array}{l}\text { Preoperative } 65.50 \pm 7.59 \text {, postoperative } \\
74.09 \pm 9.60\end{array}$ \\
\hline \multirow[t]{4}{*}{10.} & \multicolumn{7}{|c|}{ Present cadaveric model } \\
\hline & $\begin{array}{l}\text { A. Single-step step- } \\
\text { ladder } 40 \text {-degree } \\
\text { plate angle }\end{array}$ & & & & 3.15 & 1.4 & \\
\hline & $\begin{array}{l}\text { B. Single-step step- } \\
\text { ladder 17-degree } \\
\text { plate angle }\end{array}$ & & & & 2.52 & 0.8 & \\
\hline & $\begin{array}{l}\text { C. Fixed gradual slope } \\
\text { model }\end{array}$ & & & & 2.58 & 0.88 & \\
\hline
\end{tabular}

Abbreviations: CT, computed tomography; SD, standard deviation. 
While conceptualizing the step-ladder cranioplasty, it was thought that the volume augmentation is based solely on the cranial thickness ${ }^{1-3}$ and a two-step step-ladder cranioplasty was thought to be the answer in individuals with skull thickness less than $7 \mathrm{~mm} .{ }^{1,2}$ In this cadaveric study, it was realized that there is another important factor that contributes to volume augmentation. This second factor is the angulation achieved by the titanium miniplates with a tangent drawn to the cranial surface at that point. In the cadaveric model, an increase in the angle from 13 to 40 degrees resulted in an increase in the outward

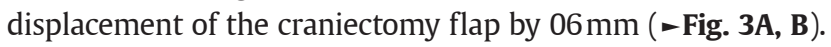
Coring the central part of the bone flap till the outer plate can further increase the available volume ( - Fig. 2D).

In the first case report of step-ladder cranioplasty, ${ }^{3}$ possibility of bony nonunion and poor cosmetic result were reported as two obvious ill effects of the procedure. Two new concepts were tried on this cadaveric model to resolve the issues. The aim was to have partial contact of the bone edges to increase the possibility of bony union and a gradual slope of the stepwise increase in height to avoid an obvious step deformity (-Fig. 3).

In the "floating" step-ladder variant, volume augmentation $\left(\mathrm{V}_{1}\right)$ will have two components:

1. Fixed (assured) component $\left(\mathrm{V}_{1 \mathrm{f}}\right)$, equivalent to half the thickness of the bone at craniectomy margin, the level at which the titanium miniplates are inserted into the cranium.

2. Fixed (likely) component $\left(\mathrm{V}_{1 \mathrm{~m}}\right)$, produced by the brain with raised ICP pushing the bone flap still further away.

Cranial bone is maximally thick from the midline to the superior temporal line. It will be of most advantage to place all the titanium mini plates in this region.

On adding $800 \mathrm{~mm}^{2}$ to, for temporal craniectomy, the size of the craniotomy defect (surface area $7,848 \mathrm{~mm}^{2}$ ) in this study was equivalent to the minimum recommended (10-cm-diameter defect with a surface area of $7,800 \mathrm{~mm}^{2}$ ). A craniotomy of $12 \mathrm{~cm}$ diameter $\left(11,300-\mathrm{mm}^{2}\right.$ surface area) will require much lesser lateral displacement of the bone flap to cause a given volume expansion., ${ }^{2,13}$

\section{Conclusion}

In this cadaveric study, the following points regarding step-ladder cranioplasty emerged clearly:

1. The cranial volume expansion is not dependent solely on skull bone thickness and the surgery can be offered to anyone irrespective of his/her skull bone thickness.

2. Provided, clinical trials prove the procedure to be safe, a single-step step-ladder cranioplasty can be used instead of preserving the bone flap at another site, to be followed by a formal cranioplasty at a later date. This will obviate host site complication, at the same time protecting the brain from trephination syndrome and external injuries.

3. For those neurosurgeons who believe that edematous brain can push hinged bone flaps along with the scalp adequately to create enough space for itself, a mobile gradual slope step-ladder cranioplasty can be an attractive alternative offering a limited assured fixed volume expansion and a possibility of additional volume expansion when required.

In the present study, a few possible variations have been thought of and studied. In an emerging concept, enormous other possibilities and variations to be imagined and worked remain. Simply replacing the titanium miniplates and screws by absorbable materials can add an absolutely new dimension.

\section{Acknowledgments}

Special thanks to our operating room assistants Mr. Bhupal Singh and Mr. Dinesh Maria and the radiology department of our hospital who worked at off-duty hours, to make this project possible.

\section{References}

1 Sengupta SK. Step-ladder expansive cranioplasty after decompressive craniotomy and expansive duraplasty: discussing possibilities on a mathematical model. Indian J Neurosurg 2015;4 (01):15-21

2 Sengupta SK, Sahni H, Rappai TJ, Verma S. Step ladder expansive cranioplasty: feasibility study on computed tomographic scan images. Indian J Neurosurg 2015;4 (02):102-108

3 Sengupta SK. Single-step step ladder expansive cranioplasty. Indian J Neurosurg 2017;6:107-112

4 Kenning TJ, Gandhi RH, German JW. A comparison of hinge craniotomy and decompressive craniectomy for the treatment of malignant intracranial hypertension: early clinical and radiographic analysis. Neurosurg Focus 2009;26 (06):E6

5 Kenning TJ, Gooch MR, Gandhi RH, Shaikh MP, Boulos AS, German JW. Cranial decompression for the treatment of malignant intracranial hypertension after ischemic cerebral infarction: decompressive craniectomy and hinge craniotomy. J Neurosurg 2012;116(06):1289-1298

6 Ko K, Segan S. In situ hinge craniectomy. Neurosurgery 2007;60 (4, 2):255-258, discussion 258-259

7 Peethambaran AK, Valsalmony J. Four-quadrant osteoplastic decompressive craniotomy: a novel technique for decompressive craniectomy avoiding revision cranioplasty after surgery. Neurol India 2012;60 (06):672-674

8 Adeleye AO, Azeez AL. Decompressive craniectomy bone flap hinged on the temporalis muscle: a new inexpensive use for an old neurosurgical technique. Surg Neurol Int 2011;2:150

9 Stoner KE, Abode-Iyamah KO, Grosland NM, Howard MA III. Volume of brain herniation in patients with ischemic stroke after decompressive craniectomy. World Neurosurg 2016;96:101-106

10 Kwon YS, Yang KH, Lee YH. Craniotomy or decompressive craniectomy for acute subdural hematomas: surgical selection and clinical outcome. Korean J Neurotrauma 2016;12 (01):22-27

11 Münch E, Horn P, Schürer L, Piepgras A, Paul T, Schmiedek P. Management of severe traumatic brain injury by decompressive craniectomy. Neurosurgery 2000;47 (02):315-322, discussion 322-323

12 Olivecrona M, Rodling-Wahlström M, Naredi S, Koskinen LO. Effective ICP reduction by decompressive craniectomy in patients with severe traumatic brain injury treated by an ICP-targeted therapy. J Neurotrauma 2007;24(06):927-935

13 Cavuşoğlu H, Kaya RA, Türkmenoğlu ON, Aydin Y. Value of early unilateral decompressive craniectomy in patients with severe traumatic brain injury. Ulus Travma Acil Cerrahi Derg 2010;16(02):119-124

14 Fletcher TL, Kolias AG, Hutchinson PJ, Sutcliffe MPF. A new improved method for assessing brain deformation after decompressive craniectomy. PLoS One 2014;9(10):e110408 